\title{
Behaviour of NiTi SMA Helical Springs under Different Temperatures and Deflections
}

\author{
R. Santhanam, ${ }^{1}$ Y. Krishna, ${ }^{1}$ and M. S. Sivakumar ${ }^{2}$ \\ ${ }^{1}$ Defence Research and Development Laboratory, Hyderabad 500 058, India \\ ${ }^{2}$ Department of Applied Mechanics, IIT Madras, Chennai 600 036, India \\ Correspondence should be addressed to R. Santhanam; santhanam1979@gmail.com
}

Received 21 May 2013; Accepted 11 June 2013

Academic Editors: Y. Ge, K. Hokamoto, V. Ji, and P. Karjalainen

Copyright (C) 2013 R. Santhanam et al. This is an open access article distributed under the Creative Commons Attribution License, which permits unrestricted use, distribution, and reproduction in any medium, provided the original work is properly cited.

\begin{abstract}
Shape memory alloys (SMAs) are one of the most widely used smart materials in many applications because of their shape memory effect property. In this work, the behaviour of NiTi SMA helical spring was evaluated through isothermal force-displacement experiment (IFDE) and shape recovery force experiment (SRFE). The transformation temperatures of SMA spring were determined by differential scanning calorimetry (DSC) test. In situ heating of SMA spring by direct electric current was used instead of conventional furnace heating. The continuous measurement of temperature of SMA spring during heating and cooling was ensured with attaching the thermocouple by heat shrinkable sleeve. From IFDE, the force-deflection behaviour under different constant temperatures and from SRFE and the force-temperature behaviour under different constant deflections are obtained. The results of IFDE show that the force increases and the residual displacement decreases with an increase in the temperature, and the stiffness of the spring at austenite state is greater than that at martensitic state. The results of SRFE show that the shape recovery force increases more or less linearly with an increase in the initial deflection for the same temperature range. But the shape recovery forces are not similar during heating and cooling stages. This paper presents the experimental setup, experimental procedures, and the observed behaviour of SMA helical springs under different temperatures and deflections.
\end{abstract}

\section{Introduction}

A shape memory alloy (SMA) has two unique properties: (1) pseudoelastic effect (PEE) or superelastic effect (SEE) and (2) shape memory effect (SME). These unique properties are achieved through a solid-state phase change (molecular rearrangement) that occurs in an SMA. The phase transition occurs between the high temperature parent phase austenite (A) and the low temperature phase martensite (M) and is referred as martensitic phase transformation. SME refers to the ability of the material, initially deformed in its low temperature phase $(\mathrm{M})$, to recover its original shape upon heating to its high temperature phase (A). Super elasticity occurs when the martensitic phase transformation is stress induced at a constant temperature which is above austenite transformation temperature. SME of the SMAs can be used for actuation, and SE of the SMAs can be used in applications such as vibration isolators and dampers. It is understood from the literature survey that many attempts have been made towards the description of the thermomechanical behavior of SMA wires under various conditions [1-4]. However, very few attempts have been made towards the description of the behavior of SMA springs under thermo-mechanical loads $[5,6]$, and hence there is lack of data available regarding the same. The present study is aimed at understanding the behaviour of NiTi shape memory alloy (SMA) springs through two experiments: (1) isothermal force-deflection experiment (IFDE) and (2) shape recovery force experiment (SRFE).

\section{Materials and Methods}

The material used is a Ti-55.84 wt\% Ni SMA. Amongst different forms of available SMAs, a closely coiled helical spring is chosen for the experiments as it can generate a larger force and stroke with smaller dimensions. In present study, commercially available Ni-Ti SMA springs have been used with dimensions: coil mean diameter is $6.4 \mathrm{~mm}$, wire 
TABLE 1: DSC results.

\begin{tabular}{lccc}
\hline \multicolumn{4}{c}{ Transformation temperatures $\left({ }^{\circ} \mathrm{C}\right)$} \\
Mf & Ms & As & Af \\
\hline 43.69 & 56.62 & 53.47 & 66.45 \\
\hline
\end{tabular}

Note: for conducting the experiments, the temperatures are taken between $25^{\circ} \mathrm{C}$ and $85^{\circ} \mathrm{C}$ which are approximately derived from Mf of DSC $-18^{\circ} \mathrm{C}$ and Af of DSC $+18^{\circ} \mathrm{C}$ to ensure that the SMA spring has reached fully austenitic/ martensitic condition.

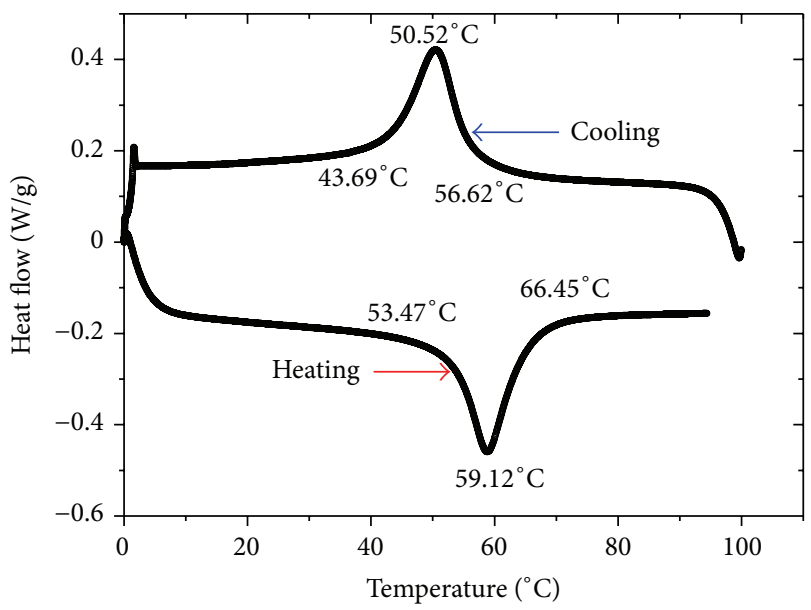

Figure 1: DSC curve.

diameter is $0.78 \mathrm{~mm}$, and the number of active coils turns is 19. The DSC curve is given in Figure 1, and the results are in Table 1.

Experimental setup consists of a test rig and an external data acquisition system (DAS). Test Rig is a motorized frame with a microprocessor controller. This Test Rig is fitted with a load cell and position transducer. It can be used to apply force on the spring with the help of movable crosshead which can travel freely up and down along the guides. This Test Rig can be used to measure the load versus displacement of SMA springs at different temperatures. National-Instrument(NI-) based DAS is used for varying and controlling the temperature of SMA springs through a power supply. In situ heating of SMA spring using direct electrical current is used in experiments, and cooling of the spring is achieved by natural convection. A K-type thermocouple with a $0.75 \mathrm{~mm}$ bead is attached to the middle coil of SMA spring using heat shrinkable sleeves for measurement of temperature. While testing the SMA springs in the Test Rig, the hooks of the SMA springs are tied to the hooks of the Test Rig using copper wires to avoid slipping of springs during contracting while heating. The block diagram of the experimental setup is shown in Figure 2.

\section{Experimental Results and Discussions}

3.1. Isothermal Force-Displacement Experiment (IFDE). SMA spring was maintained at constant temperature (isothermal) in an unstretched martensitic condition. Once the temperature of the spring reached a steady-state value, the spring was stretched from zero to $50 \mathrm{~mm}$ (this $50 \mathrm{~mm}$ is chosen due to the limitation of test setup: displacement beyond $50 \mathrm{~mm}$ is not possible to measure in the present setup) and again slowly released to zero. During this, load required to stretch the spring was measured continuously. The same experiment was repeated for different constant temperatures: $21^{\circ} \mathrm{C}$ (room temperature), $35^{\circ} \mathrm{C}, 45^{\circ} \mathrm{C}, 55^{\circ} \mathrm{C}, 65^{\circ} \mathrm{C}, 75^{\circ} \mathrm{C}$, and $85^{\circ} \mathrm{C}$. Here, temperature $(T)$ was constant, displacement $(\delta)$ was varied and controlled, and force $(F)$ was measured as output.

Force-displacement curves for different constant temperatures are shown in Figure 3(a). Figure 3(b) shows the effect of different isothermal temperatures on the force and residual displacement of SMA spring where the force increases and the residual displacement decreases with increase in temperature. The average stiffness of the spring is a function of temperature and increases with temperature based on the relation: $K=G d^{2} / 8 n D^{3}$, where $K$ is the stiffness, $G$ is the shear modulus, $d$ is the wire diameter, $n$ is the number of coils, and $D$ is the coil diameter of the SMA spring. The shear modulus $G$ increases with temperature for SMAs unlike other conventional metallic materials. Generally, $G$ of austenite $\left(G_{A}\right)$ will be 2.5 to 3 times the $G$ of martensite $\left(G_{M}\right)$. Keeping $d, n, D$ constant, $K$ depends on $G$. So, $K$ of austenite $\left(K_{A}\right)$ will be 2.5 to 3 times the $K$ of martensite $\left(K_{M}\right)$. Here $K_{A}$ is equal to $0.1036 \mathrm{~N} / \mathrm{mm}$, and $K_{M}$ is equal to $0.2708 \mathrm{~N} / \mathrm{mm}$. Measured value of stiffness shows that $K_{A}=2.61 K_{M}$.

3.2. Shape Recovery Force Experiment (SRFE). SMA spring was stretched to some known deflection in martensitic condition and constrained at initial deflected condition. Heating of constrained SMA spring generates force which is called as shape recovery force (SRF). This experiment was conducted for various initial deflections such as $10 \mathrm{~mm}, 20 \mathrm{~mm}, 30 \mathrm{~mm}$, $40 \mathrm{~mm}$, and $50 \mathrm{~mm}$. The SMA spring was heated from $21^{\circ} \mathrm{C}$ to $95^{\circ} \mathrm{C}$ and again cooled to $25^{\circ} \mathrm{C}$. Here, displacement $(\delta)$ was constant, temperature $(T)$ was varied and controlled and force $(F)$ was measured as output.

Figure 4(a) shows the force-temperature curves for all deflections. After the spring is kept in an initial deflected condition, when SMA spring has reached the temperature of Af (about $95^{\circ} \mathrm{C}$ ), after the electrical power supply is switched on, a maximum force is generated. When the power is switched off, the temperature of the spring drops and the force decreases. The force of the spring decreases significantly when the temperature drops to $25^{\circ} \mathrm{C}$. It is noted that for all the deflections, the starting force values are different and the force values practically returns to zero when the temperature reaches $25^{\circ} \mathrm{C}$. But, it can be clearly seen from the trends of the curves in Figure 4(a) that the SRF of SMA spring increases with increasing initial deflections for the same temperature of $21^{\circ} \mathrm{C}$ to around $95^{\circ} \mathrm{C}$. From the temperature-force heating curves of all initial deflections in Figure 4(a), the variation is linear up to certain temperatures $\left(10 \mathrm{~mm}>38^{\circ} \mathrm{C}, 20 \mathrm{~mm}>40^{\circ} \mathrm{C}, 30 \mathrm{~mm}>41^{\circ} \mathrm{C}, 40 \mathrm{~mm}>\right.$ $43^{\circ} \mathrm{C}$, and $50 \mathrm{~mm}>47^{\circ} \mathrm{C}$ ), and deviation occurs from linearity beyond these temperature values. It is observed that the rate of force generation is independent of initial deflection, while heating and rate of force are decreased at 


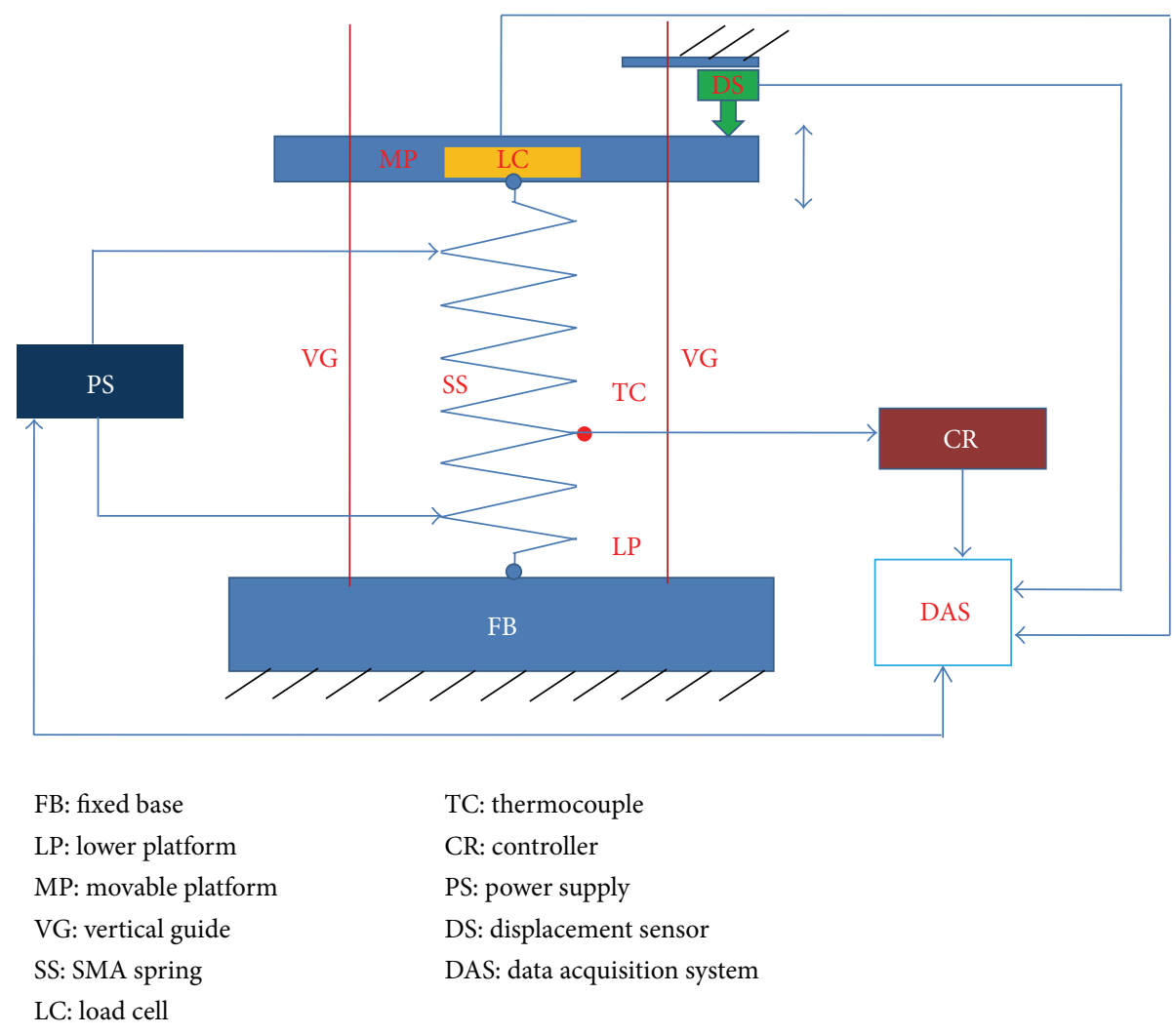

Figure 2: Block diagram of experimental setup.

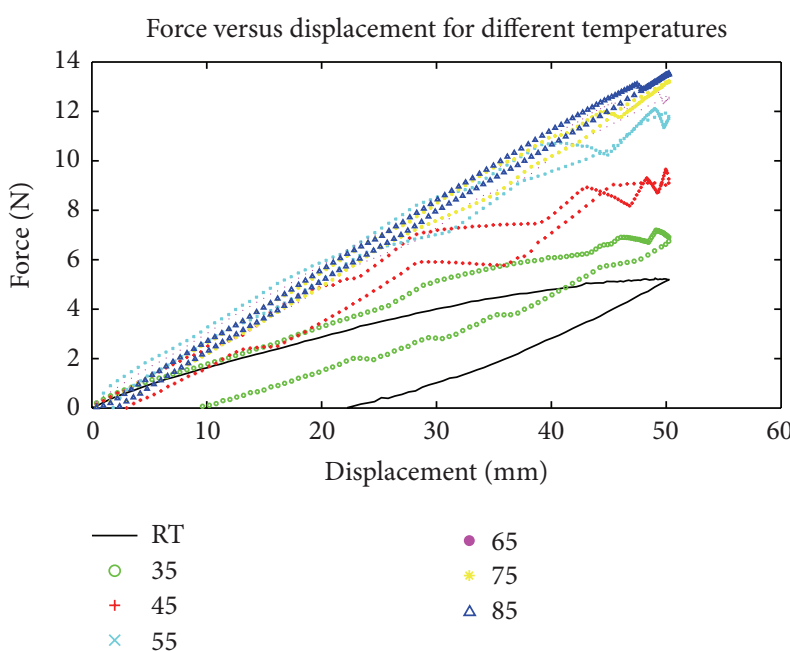

(a)

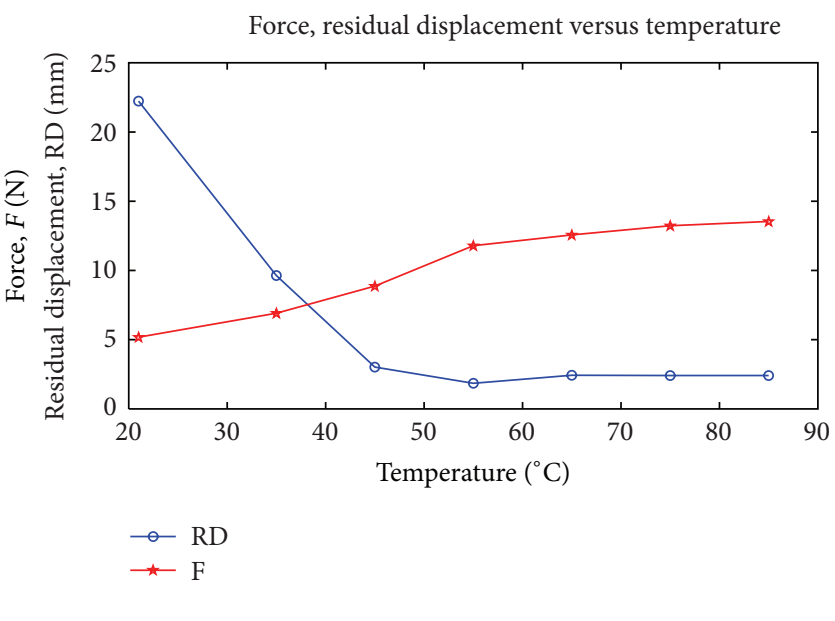

(b)

FIGURE 3: (a) Force-displacement and (b) effect of isothermal temperatures on force $(F)$ and residual displacement (RD) curves from IFDE.

different rate while cooling. Figure 4(b) shows the effect of initial deflections on maximum SRF where it is seen that the higher the initial deflections are, the more the recovery force generated is. It shows fairly a linear relation with a linear fit given by $y=0.2447 x-1.737$, where $y$ is maximum SRF (at $90^{\circ} \mathrm{C}$ ) and $x$ is the initial deflection.

\section{Conclusions}

The behaviour of NiTi SMA helical spring was evaluated through IFD and SRF experiments. A closely coiled helical spring is chosen for the experiments out of various forms of SMAs as it can generate a larger force and stroke with 


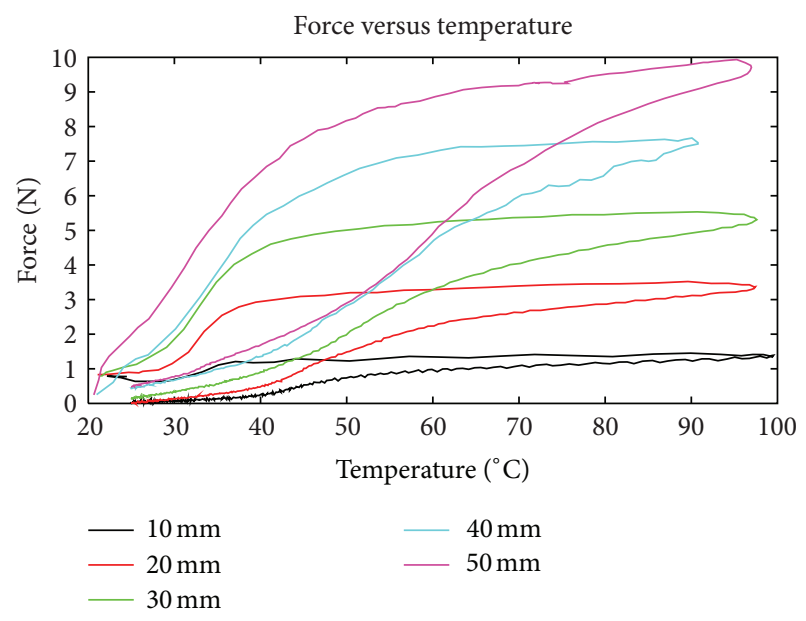

(a)

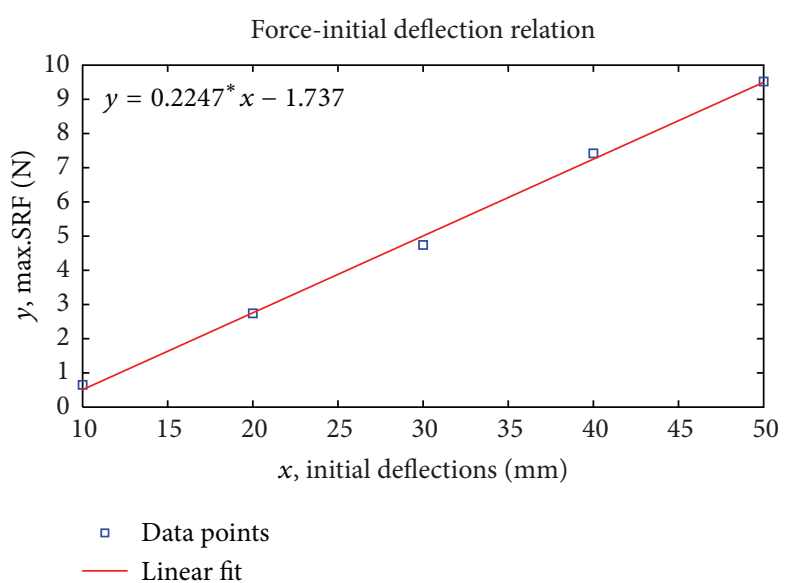

(b)

FIGURE 4: (a) Force-temperature for heating and cooling and (b) force-initial deflection relation from SRFE.

smaller dimensions. The results from IFD experiments show that force increases with increase in temperature and residual displacement decreases with the increase in temperature. Also the stiffness of the spring at austenite state is around 2.61 times the stiffness of the spring at martensitic state. The results of SRF Experiments show that shape recovery force increases with the increase in the initial deflection for the same temperature range. The relation between the maximum SRF and initial deflection is fairly linear. But SRF curves during heating and cooling stages are not similar because of the hysteretic nature of SMAs. These results are in accord with the previous experimental studies found in the literature. This information is very useful for using SMA springs as sensors and actuators for one time applications.

\section{Acknowledgments}

The first author would like to thank Director, DRDL, Hyderabad, India for giving permission to pursue this research topic. The first author also would like to thank Dr. Aroute Chelvane of DMRL, Hyderabad, India, Dr. Vijaya Baskar of RCI, Hyderabad, India and Dr. John Rozario Jegaraj of DRDL, Hyderabad, India for helpful discussions and valuable suggestions.

\section{References}

[1] M. Wagner, T. Sawaguchi, G. Kaustrater, D. Hoffken, and G. Eggeler, "Structural fatigue of pseudoelastic NiTi shape memory wires," Materials Science and Engineering A, vol. 378, no. 1-2, pp. 105-109, 2004.

[2] H. Tobushi, T. Hachisuka, S. Yamada, and P.-H. Lin, "Rotatingbending fatigue of a TiNi shape-memory alloy wire," Mechanics of Materials, vol. 26, pp. 35-42, 1997.

[3] G. Eggeler, E. Hornbogen, A. Yawny, A. Heckmann, and M. Wagner, "Structural and functional fatigue of NiTi shape memory alloys," Materials Science and Engineering A, vol. 378, no. 1-2, pp. 24-33, 2004.
[4] D. C. Lagoudas, P. B. Entchev, and P. K. Kumar, "Thermomechanical characterization of SMA actuators under cyclic loading," in Proceedings of the ASME International Mechanical Engineering Congress, Washington, DC, USA, November 2003.

[5] H. J. Lee and J. J. Lee, "Evaluation of the characteristics of a shape memory alloy spring actuator," Smart Materials and Structures, vol. 9, no. 6, pp. 817-823, 2000.

[6] R. A. A. Aguiar, M. A. Savi, and P. M. C. L. Pacheco, "Experimental and numerical investigations of shape memory alloy helical springs," Smart Materials and Structures, vol. 19, no. 2, Article ID 025008, 9 pages, 2010. 

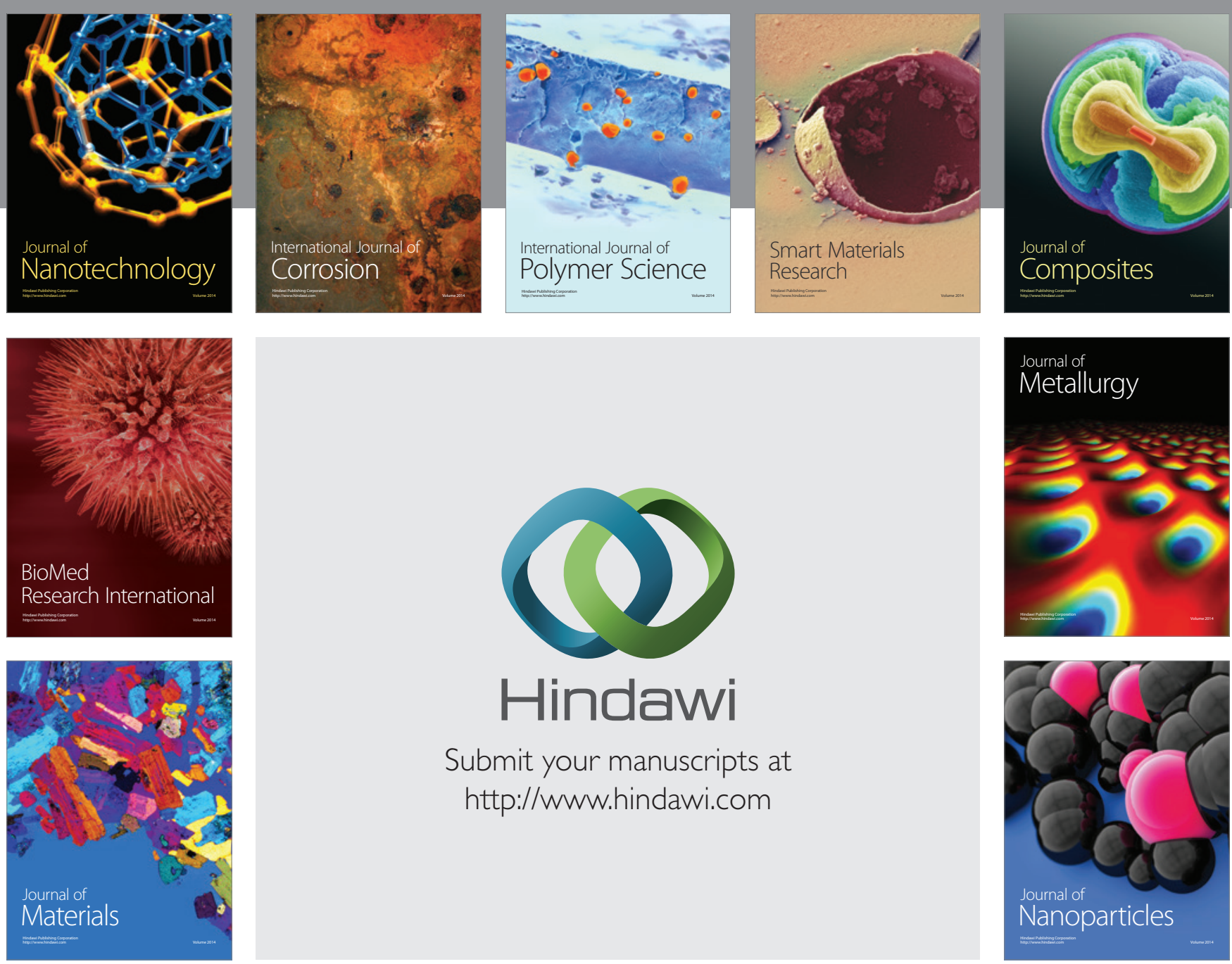

Submit your manuscripts at http://www.hindawi.com
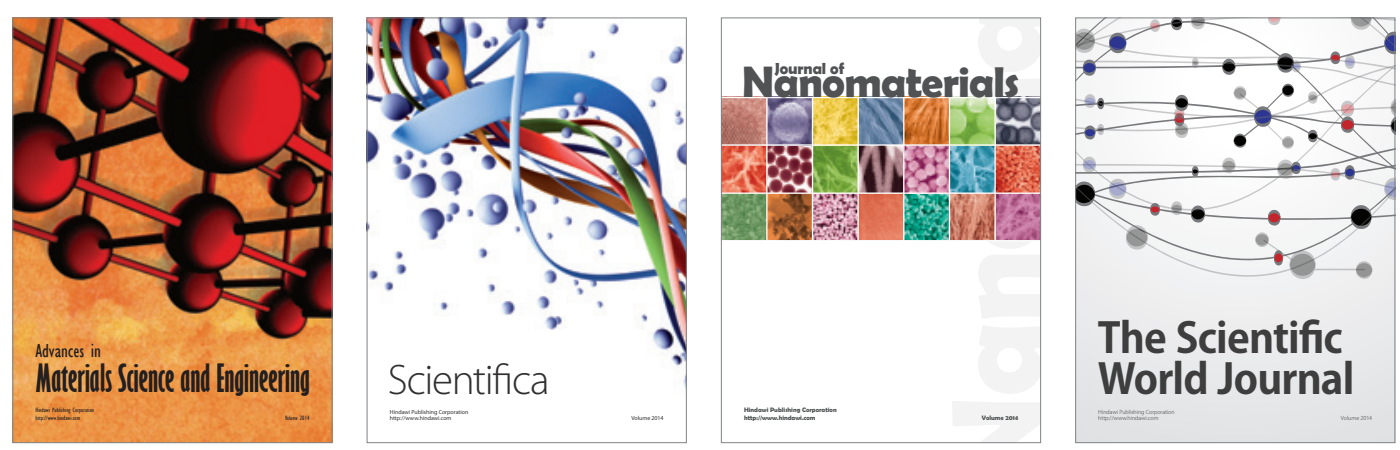

\section{The Scientific World Journal}
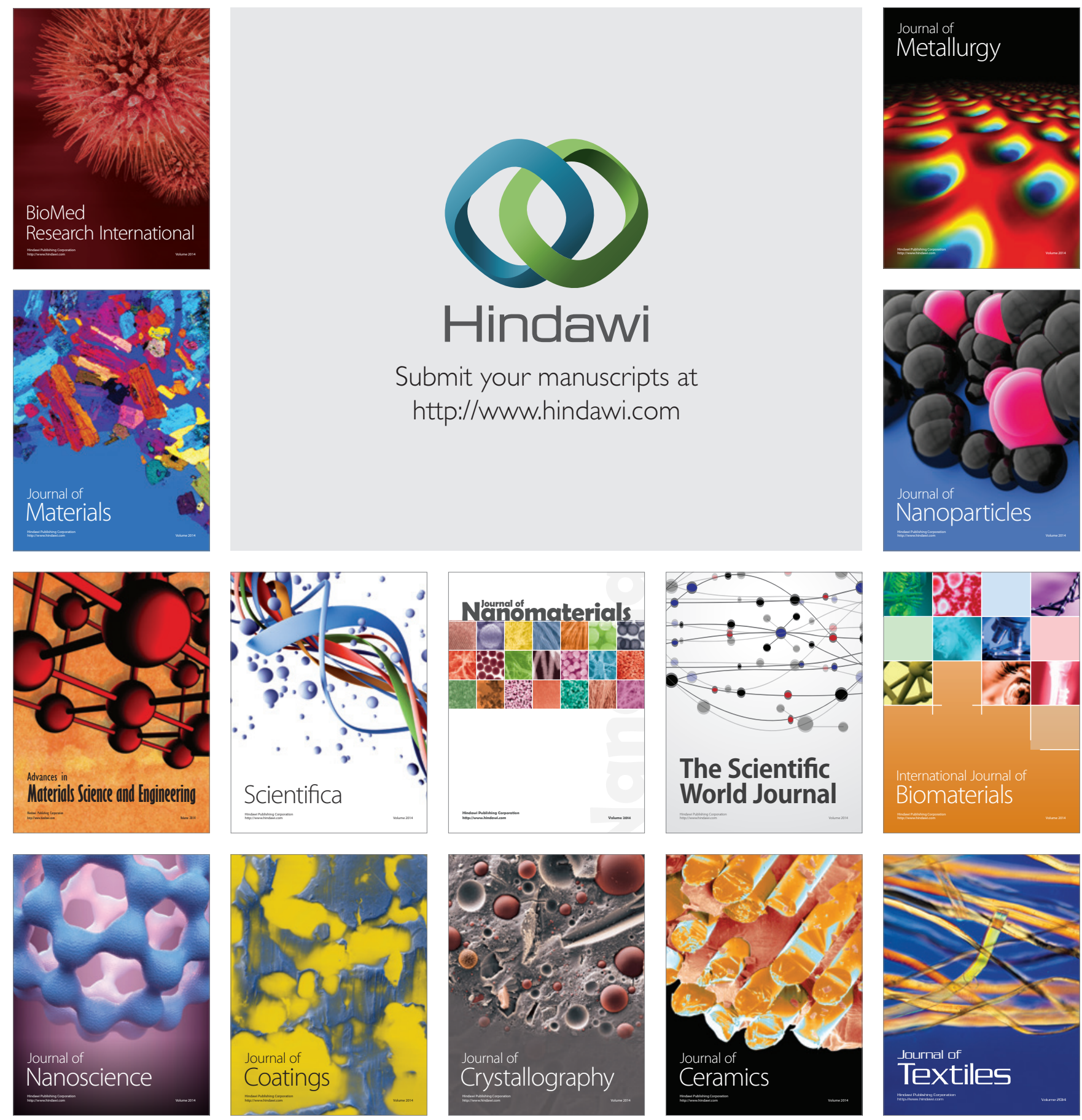